\title{
MUSCLE ACTION POTENTIAL SCANS AND ULTRASOUND IMAGING IN NEUROFIBROMATOSIS Type 2
}

\begin{tabular}{|r|l|}
\hline Journal: & Muscle and Nerve \\
\hline Manuscript ID & MUS-15-0945.R2 \\
\hline Wiley - Manuscript type: & Research Article \\
\hline Date Submitted by the Author: & n/a \\
\hline Complete List of Authors: & $\begin{array}{l}\text { Farschtschi, Said; Universitatsklinikum Hamburg-Eppendorf, Neurology } \\
\text { Gelderblom, Mathias; Universitatsklinikum Hamburg-Eppendorf, Neurology } \\
\text { Buschbaum, Sabriena; Universitatsklinikum Hamburg-Eppendorf, } \\
\text { Neurology } \\
\text { Bostock, Hugh; Institute of Neurology, Sobell Department } \\
\text { Grafe, Peter; Ludwig-Maximilians-Universitat Munchen, Physiology } \\
\text { Mautner, Victor-Felix; Universitatsklinikum Hamburg-Eppendorf, Neurology }\end{array}$ \\
\hline Keywords: & $\begin{array}{l}\text { neurofibromatosis type 2, MUNE, denervation, reinnervation, neuropathy, } \\
\text { utrasound nerve imaging }\end{array}$ \\
\hline \multicolumn{2}{|c|}{} \\
\hline
\end{tabular}

SCHOLARONE ${ }^{\text {m }}$

Manuscripts 


\title{
MUSCLE ACTION POTENTIAL SCANS AND ULTRASOUND
}

\section{IMAGING IN NEUROFIBROMATOSIS Type 2}

\author{
SAID FARSCHTSCHI, $\mathrm{MD}^{1 \dagger}$, MATHIAS GELDERBLOM, $\mathrm{MD}^{1 \dagger}$, SABRIENA \\ BUSCHBAUM ${ }^{1}$, HUGH BOSTOCK, $\mathrm{PhD}^{2}$, PETER GRAFE, MD $\mathrm{PhD}^{3}$ and VICTOR F. \\ MAUTNER, MD PhD ${ }^{1}$ \\ ${ }^{1}$ Department of Neurology, University Medical Centre Hamburg-Eppendorf Hospital, \\ Hamburg, Germany \\ ${ }^{2}$ Sobell Department of Motor Neuroscience and Movement Disorders, Institute of Neurology, \\ University College London, London, UK \\ ${ }^{3}$ Physiological Genomics, Institute of Physiology, Ludwig-Maximilians University Munich, \\ Munich, Germany
}

$\dagger$ These two authors contributed equally to the publication as first authors

\section{Acknowledgments}

We would like to thank our patients for their valuable cooperation in this study. We highly appreciate the work of Mr. Jan Luhmann, who supported technical assistance. This study was funded by the "Märta and Erik Karberg Foundation for Medical Research" and the young investigator award of the neurofibromatosis lay organization "Bundesverband

Neurofibromatose".

\section{Corresponding author:}

Prof. Dr. Peter Grafe

Institute of Physiology

University of Munich

Pettenkoferstr. 12

80336 Munich

e-mail: P.Grafe@1rz.uni-muenchen.de

Running title: CMAP scans and nerve imaging in NF2 


\title{
MUSCLE ACTION POTENTIAL SCANS AND ULTRASOUND IMAGING IN NEUROFIBROMATOSIS Type 2
}

\author{
ABSTRACT \\ Introduction: The neuropathy in patients with neurofibromatosis type 2 (NF2) is difficult to \\ quantify and to follow-up. This study compared three methods which may help to assess \\ motor axon pathology in NF2 patients. \\ Methods: Nerve conduction studies in median nerves were supplemented by deriving motor \\ unit number estimates (MUNE) from compound muscle action potential (CMAP) scans, and \\ by high resolution ultrasound (US) peripheral nerve imaging. \\ Results: CMAP amplitudes and nerve conduction velocity were normal in the vast majority of \\ affected individuals, but CMAP scan MUNE revealed denervation and reinnervation in many \\ of the peripheral nerves in NF2 patients. In addition, US nerve imaging enabled to monitor the \\ size and number of schwannoma-like fascicular enlargements in the median nerve trunks. \\ Conclusion: In contrast to conventional nerve conductions studies, CMAP scan MUNE in \\ combination with US nerve imaging can quantify the NF2-associated neuropathy and may \\ help to monitor disease progression and drug treatments.
}

Key words: neurofibromatosis type 2, MUNE, denervation, reinnervation, ultrasound nerve imaging, neuropathy 


\section{INTRODUCTION}

Neurofibromatosis type 2 (NF2) is a hereditary tumor syndrome caused by loss of function mutations or deletion of the neurofibromatosis type 2 gene (NF2) located on chromosome 22q12. ${ }^{1}$ This gene encodes merlin, a multi-functional cellular protein (see ${ }^{2}$ for a recent review). Symptoms of neuropathy are common in NF2 as there are paresthesias, sensory loss, weakness, and muscle atrophy. Neuropathic pain, however, occurs in few patients only. ${ }^{3-7}$ The aim of the present study was to test novel methods which may help to quantify and follow up the NF2-associated neuropathy. For example, in the last few years, attempts to treat NF2 with pharmacological tools have led to the discovery that the anti-vascular antibody bevacizumab can at least stop the growth of tumors in many NF2 patients (e.g. $\left.{ }^{8-10}\right)$. In addition, it has been described, recently, that an anti-angiogenesis treatment can improve the neuropathy in a murine sciatic nerve model of NF2. ${ }^{11}$ However, the effect of pharmacological treatment strategies on the NF2-associated neuropathy in patients has not yet been described. One reason for this may be the lack of methods suitable to quantify motor axon pathology in NF2.

A conventional electrophysiological examination of peripheral nerves includes, among other parameters, the determination of the amplitude of CMAPs. This parameter, however, offers only a rough estimation of the number of functionally intact motor axons in peripheral nerves. Reinnervation by collateral sprouting may keep the amplitude constant in spite of a loss in the number of motor units and axons. ${ }^{12,13}$ In fact, apparently normal CMAPs have been recorded in amyotrophic lateral sclerosis (ALS) although the number of intact motor axons was reduced by $50 \% .^{14}$

In the last years, several methods have been developed to estimate the number of intact motor units in a peripheral nerve (MUNE). ${ }^{15-17}$ It is now an accepted view that concurrent tracking of declines in MUNE and changes in single motor unit size over time have proven useful for research into the natural history of denervating disease, as well as the compensatory effects of collateral reinnervation. ${ }^{17}$ 
Muscle action potential scans (CMAP scans), too, have been found to be useful in several types of motor neuron diseases and neuropathies. ${ }^{18,19}$ In the present study, we have used the MScanFit program, recently developed by one of the authors (HB) to model a CMAP scan. ${ }^{20}$ Here we demonstrate that this analysis software can reveal denervation, but also reinnervation in peripheral nerves and muscles in NF2 patients.

Peripheral nerve imaging carried out by high resolution ultrasound techniques can be performed with high spatial resolution ${ }^{21}$ and findings on the median nerve have already been described. ${ }^{\text {e.g. }}{ }^{22-24}$ It has been shown that his method allows the detection and quantification of schwannomas in peripheral nerves. ${ }^{25}$ In the present study, we have combined CMAP scan MUNE with ultrasound imaging (US) to test whether these methods may help to quantify and to follow-up the NF2-associated neuropathy. 


\section{MATERIALS and METHODS}

\section{Patients}

The study is based on measurements of 19 NF2 patients aged between 12 to 70 years (mean \pm SE: $34.5 \pm 2.9$ years; 12 males, 7 females). The diagnosis of NF2 in these patients was established on the basis of the modified NIH criteria for definite NF2 ${ }^{26}$ and verified by genetic testing. Other concurring causes for a neuropathy such as diabetes mellitus, alcoholism etc. were excluded by means of medical history and laboratory testing. All procedures were approved by the local ethics committee of Hamburg University Hospital and all patients gave written formal consent. Not all patients were examined by both, electrophysiology and nerve ultrasound imaging on both arms. This is due to organizational reasons (studies in two clinical departments), a change in the study design from one arm to both arms, and insufficient CMAP recordings (see Results for details).

\section{Electrophysiology}

The CMAP scans were performed in the neurofibromatosis outpatient clinic of the HamburgEppendorf University Hospital. QTRACW software (C Institute of Neurology, London) was available on a laptop with a Windows7 operating system. The other components of the set-up were the DS5 isolated bipolar constant current stimulator (Digitimer Ltd; Welwyn Garden City, UK), National Instruments USB-6251-BNC data acquisition device (National Instruments Munich; Germany), the Hum Bug $50 \mathrm{~Hz}$ noise eliminator (Science Products; Hofheim, Germany), and a Grass LP511 AC amplifier; bandwith: 3 - 3 kHz. Self adhesive electrodes (Kendall ECG electrodes, H92SG) with a round conducting area of $15 \mathrm{~mm}$ in diameter were used for both stimulation and recording. The position of these electrodes were as in conventional use, stimulating the median nerve at the wrist, and recording CMAPs from the motor point of abductor pollicis brevis. For grounding, Neuroline 71410-M/1 electrodes (Ambu; Bad Nauheim, Germany) were used. 
In addition, conventional electrodiagnostic testing of the median nerve (in particular determination of nerve conduction velocities in the upper and the forearm) was performed in the neurophysiology laboratory of the Hamburg-Eppendorf University Hospital by using a Nihon Kohden Neuropack X1. In median motor nerve studies, the recording site was the abductor pollicis brevis muscle. Stimulation sites were chosen at the wrist, the antecubital fossa, and the axilla.

\section{Muscle action potential scans}

Previously, the principles of CMAP scans or electrophysiological muscle scans have been described. ${ }^{18,19}$ These authors tested the importance of variables, such as stimulation frequency, stimulus duration, and the number of stimulus steps. ${ }^{27}$. The analysis of CMAP scans is, however, not yet standardized. The method used in the present study (MScanFit) has been described in detail. ${ }^{20}$ MScanFit is available as part of the threshold tracking software QTRACW (C Institute of Neurology, University College London, distributed by Digitimer Ltd at www.digitimer.com). It was chosen for its convenience and speed. In brief, the peak CMAP amplitude was recorded while stimuli were delivered at a frequency of $2 \mathrm{~Hz}$. The stimulus current was decreased from just supramaximal in $0.2 \%$ steps to a current strength just below the one necessary for the smallest measurable surface muscle action potential. The data plots were fitted by a model, in which the CMAP was made up of a number of SMUPs, each described by an amplitude, threshold and relative spread (or coefficient of variation) of threshold. From this fitted model, the following derived parameters were used for the analyses: (1) number of SMUPs, (2) mean SMUP amplitude, and (3) largest SMUP amplitude.

\section{Ultrasound peripheral nerve imaging}

Ultrasound examinations were performed using a GE Healthcare LOGIQ E9 with a L8 18i linear hockey stick probe. To improve image quality, CrossXBeam and compound imaging software was used. Median nerves were scanned in the transverse plane along their entire 
accessible length from axilla to wrist. Cervical roots and the plexus cervicobrachialis were not scanned and, therefore, not included in the analysis. The cross-sectional area (CSA) of the median nerve was recorded at predetermined sites: at the carpal tunnel, at 1/3 of the forearm, at the elbow, at $1 / 2$ of the upper arm. Fascicle diameters were measured in each median nerve at three different sites, to generate normal diameter values $(0.6 \pm 0.13 \mathrm{~mm}$; mean $\pm \mathrm{SD})$. All "nerve lesions" within the scanned segments of the median nerve were included in the further analysis. Nerve lesions were defined as focal well defined masses inside the epineurium with a middle to low homogeneous echogeneity, which allowed a clear differentiation of the lesion from unaffected fascicles. Only masses inside the epineurium with an enlargement of the fascicle diameter $>2$ fold in comparison to the mean fascicle diameter were defined as focal "nerve lesions" or schwannoma-like fascicular enlargements. Since small nerve lesions did not results in an increase of the CSA of the affected nerve segment, the CSA was not used to define nerve lesions.

\section{Statistics}

GraphPad Prism and statistical analysis software in QTRACP were used for basic statistics and scatter plots regression lines. 


\section{RESULTS}

\section{MScanFits reveal number of functionally intact motor axons}

CMAP scans were recorded from 27 median nerves of 19 patients with NF2. The analysis is restricted to recordings with a stable amplitude of the maximal CMAP amplitude during the recording period with the maximal stimulus strength., a biphasic shape of the CMAP, no measurable responses to stimuli with low stimulation strength, the absence of disturbing 50 $\mathrm{Hz}$ noise, and no voluntary movements. Representative examples of such recordings are illustrated in Fig. 1. Illustrated in the left column of Fig. 1 are CMAPs taken at different stimulation strengths. These representative examples illustrate the shape of the CMAPs. A superposition of all traces (up to several hundred) would reduce the clarity. The MScanFit analyses shown in the center and right column estimated not only the number of functionally intact motor units, but also the relative amplitudes of the component SMUPs. Note that the maximal amplitudes of the CMAPs in the three examples of Fig. 1 are within a normal range of $5-8 \mathrm{mV}$ (from base to peak amplitude). In contrast, the numbers of functionally intact motor axons differ clearly (from 35 to 120). It can also be seen that there is an inverse relationship between the number and the mean amplitude of the SMUPs.

We also tested for a correlation between the estimated number of functionally intact motor fibers and other parameters (see Fig. 2). The graph in Fig. 2A shows, not surprisingly, that larger CMAP amplitudes tended to be made up of higher numbers of SMUPs. On the other hand, it can be seen that some CMAPs of normal amplitudes are seen in CMAP scans with a rather low number of functionally intact motor units.

No clear relationship was found between the number of motor units and the conduction velocity of the median nerve in the upper or lower arm (Fig 2B). The conduction velocity in all patients was within a normal range. On the other hand, a strong negative correlation was found between the number of functionally intact motor units and the voltage 
amplitude of SMUPs (Fig. 2C): peripheral nerves with a reduced number of motor axons show larger amplitudes of both the mean and the largest amplitude of SMUPs. This finding can be explained by reinnervation (see Discussion).

The MScan MUNE data from the NF2 patients were compared with recordings obtained from 18 control subjects (age 20-67 years; mean \pm SE : $38.6 \pm 3.5 ; 12$ females, 6 males; 26 median nerves). A summary of the findings is illustrated in Fig. 3. In several of the NF2 patients, the number of functionally intact motor units is below 70 in spite of a CMAP amplitude above $5 \mathrm{mV}$. It can be seen that an increase in the mean amplitude of SMUPs is the underlying factor.

\section{Ultrasound peripheral nerve imaging in neurofibromatosis type 2.}

The cross sectional areas along the right and left median nerves of 14 NF2 patients were measured at the carpal tunnel, at $1 / 3$ of the forearm, at the elbow, and at $1 / 2$ of the upper arm. A summary of the findings is given in Table 1. These data from NF2 patients can be compared with reference values for ultrasonograpy data of median nerves in control subjects. ${ }^{22,23}$ According to these data, we did not find a general enlargement of the CSA in the median nerves of NF2 patients.

On the other hand, a rather common observation in ultrasonographic images of NF2 patients was the presence of schwannoma-like fascicular enlargements. These are focal welldefined masses inside the perineurium with a middle to low homogeneous echogeneity, which allowed a clear differentiation from unaffected fascicles (see Fig. 3). All schwannoma-like fascicular enlargements ("nerve lesions") were in direct relationship to the median nerve. A centric location inside the median nerve was observed in $95 \%$ whereas $5 \%$ had an eccentric location. The contour exhibited well defined margins in $72 \%$, poorly defined margins were found in $28 \%$. The shape was fusiform in $87 \%$, an oval shape was found in $13 \%$. The internal echogeneity was homogeneous hypoechoic in $92 \%$, a hyperechoic echogeneity was found in 
8\%. An echogenic capsule, cystic changes, target signs or microlobulations were not found in any of the "lesions". They were distant from each other and separated by nerve segments with normal fascicular structure. We did not detect any "nerve lesions" with diffuse and multilobular enlargement, which is characteristic for plexiform neurofibromas.

Schwannoma-like fascicular enlargements ("nerve lesions") were seen in 15 median nerves of the 26 median nerves studied in 14 patients. The number of these fascicular enlargements varied between one and more than five in affected nerves. Table 2 summarizes the number and size of the "nerve lesions". The diameter varied from $>1.6 \mathrm{~mm}$ to $7 \mathrm{~mm}$. For comparison, Schreiber et al. ${ }^{22}$ reported, for controls, a fascicular diameter in the forearm median nerve of $0.60 \pm 0.21 \mathrm{~mm}($ mean $\pm \mathrm{SD})$.

\section{Do schwannoma-like fascicular enlargements correlate with CMAP scan MUNE?}

In 14 NF2 patients, both CMAP scan MUNE and high resolution US images were obtained from 19 median nerves. We tested whether the number and size (diameter) of the schwannoma-like fascicular enlargements are correlated with the loss of functionally intact motor axons in the median nerves of these NF2 patients. The data are illustrated in Fig. 4. There was a correlation between the number of lesions and the loss of functionally intact motor units. However, the regression line did not reach significance $(p=0.065)$. This may be due to some patients in which denervation of the thenar muscle, but no "nerve lesions" were found. Furthermore, the diameter of the largest schwannoma-like fascicular enlargements clearly did not show a statistically significant correlation with the loss of functionally intact motor units. There might be more and larger "nerve lesions" in more proximal parts of the motor nerve fibers not covered by the US imaging in the present study. 


\section{DISCUSSION}

In the present study of NF2 patients, parameters of conventional neurography (maximal amplitude of the CMAP and nerve conduction velocity (CV)) were supplemented by CMAP scan MUNE and US imaging. The low amplitudes of the CMAP in some patients, together with normal CVs (Fig. 2), are in accordance with the description of an "axonal" type of neuropathy in NF2 patients. ${ }^{3,5,6}$ In comparison to conventional techniques, however, the CMAP scan analyses can provide more quantitative data about the number of functionally intact motor axons in peripheral nerves and can help to quantify the extent of denervation. For example, a rather low number of motor units can be seen although the maximal amplitude of the CMAP is in the normal range (Fig. 2A).

In addition, denervation is correlated with an increase in the voltage amplitude of SMUPs. In fact, the mean amplitude of SMUPs is larger in nerves with low as compared to high numbers of functionally intact motor fibers (Fig.2C). This observation is similar to earlier reports about the characteristics of SMUPs in $\mathrm{NF}^{3}$ and other partially denervated muscles such as in ALS, CMT, diabetic neuropathy and chronic demyelinating neuropathies. 12,19, 28-31 According to these studies, it is very likely that reinnervation of denervated muscle endplates by means of axonal collateral sprouting ${ }^{12}$ is the underlying mechanism in NF2 patients, too. Taken together, the combination of a low number of functionally intact motor units and an increase in the mean amplitude of SMUPs (see Fig. 3) may help to support the diagnosis of neuropathy in NF2 patients.

The high resolution ultrasonography nerve images revealed the presence of "nerve lesions" (i.e. schwannoma-like fascicular enlargements) in many NF2 patients (Fig. 4). These lesions might be small tumors (schwannomas) composed of proliferating Schwann cells as described in histological studies of sural nerve biopsies in NF2 patients. ${ }^{3-6,32}$ It has been described already that nerve schwannomas can be detected by ultrasound imaging and a case 
report of a single NF2 patient has been published. ${ }^{25,33}$ Furthermore, multiple schwannomas along peripheral nerve trunks have been found in a recently developed murine model of NF2. ${ }^{34}$ It is, however, important to note that US imaging in the present study is restricted to the trunk of the median nerve between wrist and axilla. On the other hand, the follow-up of such known "nerve lesions" may be sufficient, for example, to monitor the effect of drug treatments on the size of peripheral nerve tumors in NF2.

The second parameter tested by US imaging in our study was the cross sectional areas of several regions in the median nerves outside schwannoma-like fascicular enlargements. The CSA data, however, did not differ from recently published reference values for ultrasonography of peripheral nerves (Table 1). ${ }^{22,23}$ It remains unclear, therefore, why nerve lesions/tumors in NF2 patients are restricted to few nerve regions only.

By demonstrating specific ultrasound changes in NF2 patients our study shows, that high resolution ultrasound can support the differential diagnosis of NF2-associated neuropathies from other hereditary or acquired neuropathies and also entrapment syndromes. In contrast to hereditary demyelinating neuropathies, e.g. CMT-1a and CMT-1b, we did not see a diffuse and extensive enlargement of the cross sectional area or fascicular diameter of the median nerve. ${ }^{22,24,35}$ In NF2 patients, CSA values and fascicular diameter did not differ from standard values in unaffected nerve segments. Nerve segments at entrapments sites, e.g. the carpal tunnel, were similarly not affected in NF2 patients, allowing a differentiation from patients with hereditary neuropathy with liability to pressure palsies (HNPP) or entrapment syndromes. ${ }^{24}$

Focal nerve enlargements are also described for acquired inflammatory demyelinating neuropathies, e.g. chronic inflammatory demyelinating polyradiculoneuropathy (CIDP). In CIDP patients either diffuse (37-41\%) or multifocal enlargement of nerves is reported. ${ }^{35,36}$ Another ultrasound pattern seen in CIDP patients are large nerves with hypoand hyperechoic fascicles. ${ }^{37}$ As discussed above we did not find similar diffuse or multifocal 
enlargements of the nerves / fascicles or changes in echogenicity in NF2 patients. In the NF2 cohort, increased CSA values were only detectable in short and clearly defined segments associated with schwannoma-like fascicular enlargements.

Only few reports describe ultrasound images of tumors associated with large sensomotoric peripheral nerves in NF1. ${ }^{38-40}$ These appear with low homogeneous echogeneity in single or multiple fascicles. Recently, possible criteria to distinguish neurofibroma from schwannoma in high resolution US nerve images have been discussed. ${ }^{41}$ We would like to emphasize that all patients in our study were diagnosed as NF2 according to current diagnostic criteria.

The pathogenesis of neuropathy in NF2 patients is unclear. We, therefore, have analyzed our data to see whether they may support one of the hypotheses. One possible factor is the cumulative nerve compression caused by small tumors (schwannomas) or fascicular microlesions as discussed in earlier studies. ${ }^{3-7,32}$ Our data can give some support for this view. They indicate that the number of "nerve lesions" is higher in nerves with a loss of functionally intact motor axons (Fig. 5). The statistical analysis of this correlation, however, does not reach significance (Fig. 5). This may indicate that some tumors remain undetected by the nerve US imaging applied in the present study, which was restricted to the median nerve distally from the axilla. Also, we cannot exclude the possibility that other factors produce denervation in NF2 patients. Indeed, a clinical study describes that NF2 may affect peripheral nerve structures in a manner distinct from a compressive schwannoma. ${ }^{42}$

Referring to this, it has been described that the loss or diminution of merlin in peripheral nerve fibers may cause the neuropathy in NF2 patients independently from the presence of Schwann cell tumors. ${ }^{43-45}$ The authors discuss an important role of merlin in neuronal cell types concerning neuromorphogenesis, axon structure maintenance and communication between axons and Schwann cells. It is possible, therefore, that NF2-related neuropathy is of multifactorial origin (Helen Morrison in ${ }^{46}$ ). Also, there might be a 
combination of several factors. For example, small lesions due to proliferating Schwann cells may be atypically destructive to axons with abnormal expression of merlin. Such a combination of factors could explain why there is an asymmetric dysfunction of motor axons in some NF2 patients and why the functionally intact axons retain the ability for collateral sprouting.

In summary, our data show that CMAP scan MUNE and high-resolution US peripheral nerve imaging are useful complimentary methods for assessing neuropathy in NF2 patients. These non-invasive methods may be helpful not only for the diagnosis but also to follow-up the time course of muscle denervation and reinnervation. In addition, repeated nerve imaging would enable to observe the development in the number and size of schwannoma-like fascicular enlargements. From a practical point of view, these methods would be feasible for routine use in specialized centers. 


\begin{abstract}
Abbreviations
\end{abstract}

$\begin{array}{ll}\text { APB } & \text { M. abductor pollicis brevis } \\ \text { ALS } & \text { amyotrophic lateral sclerosis } \\ \text { CIDP } & \text { chronic inflammatory demyelinating polyradiculoneuropathy } \\ \text { CMAP } & \text { compound muscle action potential } \\ \text { CMT } & \text { Charcot-Marie-Tooth neuropathy } \\ \text { CSA } & \text { cross sectional area } \\ \text { CV } & \text { conduction velocity } \\ \text { HNPP } & \text { hereditary neuropathy with liability to pressure palsies } \\ \text { MScan } & \text { muscle action potential scan } \\ \text { MUNE } & \text { motor unit number estimate } \\ \text { NF1 } & \text { neurofibromatosis type 1 } \\ \text { NF2 } & \text { neurofibromatosis type 2 } \\ \text { SMUP } & \text { single motor unit action potential } \\ \text { US } & \text { ultrasound }\end{array}$




\section{References}

1. Zhou L, Hanemann CO. Merlin, a multi-suppressor from cell membrane to the nucleus. FEBS Lett 2012; 586:1403-1408.

2. Petrilli AM, Fernandez-Valle C. Role of Merlin/NF2 inactivation in tumor biology. Oncogene 2015.

3. Gijtenbeek JM, Gabreels-Festen AA, Lammens M, Zwarts MJ, van Engelen BG. Mononeuropathy multiplex as the initial manifestation of neurofibromatosis type 2 . Neurology 2001; 56:1766-1768.

4. Hagel C, Lindenau M, Lamszus K, Kluwe L, Stavrou D, Mautner VF. Polyneuropathy in neurofibromatosis 2: clinical findings, molecular genetics and neuropathological alterations in sural nerve biopsy specimens. Acta Neuropathol (Berl ) 2002; 104:179187.

5. Sperfeld AD, Hein C, Schröder JM, Ludolph AC, Hanemann CO. Occurrence and characterization of peripheral nerve involvement in neurofibromatosis type 2 . Brain $2002 ; 125: 996-1004$.

6. Kuo HC, Chen SR, Jung SM, Wu Chou YH, Huang CC, Chuang WL, et al. Neurofibromatosis 2 with peripheral neuropathies: Electrophysiological, pathological and genetic studies of a Taiwanese family. Neuropathology 2010; 30:515-523.

7. Bäumer P, Mautner VF, Bäumer T, Schuhmann MU, Tatagiba M, Heiland S, et al. Accumulation of non-compressive fascicular lesions underlies NF2 polyneuropathy. J Neurol 2013; 260:38-46.

8. Plotkin SR, Stemmer-Rachamimov AO, Barker FG, Halpin C, Padera TP, Tyrrell A, et al. Hearing improvement after bevacizumab in patients with neurofibromatosis type 2 . $\mathrm{N}$ Engl J Med 2009; 361:358-367. 
9. Mautner VF, Nguyen R, Kutta H, Fuensterer C, Bokemeyer C, Hagel C, et al. Bevacizumab induces regression of vestibular schwannomas in patients with neurofibromatosis type 2. Neuro Oncol 2010; 12:14-18.

10. Plotkin SR, Merker VL, Halpin C, Jennings D, Mckenna MJ, Harris GJ, et al. Bevacizumab for progressive vestibular schwannoma in neurofibromatosis type 2: a retrospective review of 31 patients. Otol Neurotol 2012; 33:1046-1052.

11. Gao X, Zhao Y, Stemmer-Rachamimov AO, Liu H, Huang P, Chin S, et al. Anti-VEGF treatment improves neurological function and augments radiation response in NF2 schwannoma model. Proc Natl Acad Sci U S A 2015; 112:14676-14681.

12. McComas AJ, Sica RE, Campbell MJ, Upton AR. Functional compensation in partially denervated muscles. J Neurol Neurosurg Psychiatry 1971; 34:453-460.

13. Nandedkar SD, Barkhaus PE, Stalberg EV. Motor unit number index (MUNIX): principle, method, and findings in healthy subjects and in patients with motor neuron disease. Muscle Nerve 2010; 42:798-807.

14. Aggarwal A, Nicholson G. Detection of preclinical motor neurone loss in SOD1 mutation carriers using motor unit number estimation. J Neurol Neurosurg Psychiatry 2002; 73:199-201.

15. McComas AJ. Invited review: motor unit estimation: methods, results, and present status. Muscle Nerve 1991; 14:585-597.

16. Shefner JM. Motor unit number estimation in human neurological diseases and animal models. Clin Neurophysiol 2001; 112:955-964.

17. Gooch CL, Doherty TJ, Chan KM, Bromberg MB, Lewis RA, Stashuk DW, et al. Motor unit number estimation: A technology and literature review. Muscle Nerve 2014; 50:884-893.

18. Blok JH, Ruitenberg A, Maathuis EM, Visser GH. The electrophysiological muscle scan. Muscle Nerve 2007; 36:436-446. 
19. Maathuis EM, Drenthen J, Van Doorn PA, Visser GH, Blok JH. The CMAP scan as a tool to monitor disease progression in ALS and PMA. Amyotroph Lateral Scler Frontotemporal Degener 2013; 14:217-223.

20. Bostock H. Estimating motor unit numbers from a CMAP scan. Muscle Nerve; Published online: Oct 19, 2015. DOI: 10.1002/mus.24945.

21. Ohana M, Moser T, Moussaoui A, Kremer S, Carlier RY, Liverneaux P, et al. Current and future imaging of the peripheral nervous system. Diagn Interv Imaging 2014; 95:1726.

22. Schreiber S, Oldag A, Kornblum C, Kollewe K, Kropf S, Schoenfeld A, et al. Sonography of the median nerve in CMT1A, CMT2A, CMTX, and HNPP. Muscle Nerve 2013; 47:385-395.

23. Qrimli M, Ebadi H, Breiner A, Siddiqui H, Alabdali M, Abraham A, et al. Reference values for ultrasonograpy of peripheral nerves. Muscle Nerve 2016; 53:538-544.

24. Grimm A, Rasenack M, Athanasopoulou IM, Dammeier NM, Lipski C, Wolking S, et al. The modified ultrasound pattern sum score mUPSS as additional diagnostic tool for genetically distinct hereditary neuropathies. J Neurol 2016; 263:221-230.

25. Tsai WC, Chiou HJ, Chou YH, Wang HK, Chiou SY, Chang CY. Differentiation between schwannomas and neurofibromas in the extremities and superficial body: the role of high-resolution and color Doppler ultrasonography. J Ultrasound Med 2008; 27:161-166.

26. Gutmann DH, Aylsworth A, Carey JC, Korf B, Marks J, Pyeritz RE, et al. The diagnostic evaluation and multidisciplinary management of neurofibromatosis 1 and neurofibromatosis 2. JAMA 1997; 278:51-57.

27. Maathuis EM, Henderson RD, Drenthen J, Hutchinson NM, Daube JR, Blok JH, et al. Optimal stimulation settings for CMAP scan registrations. J Brachial Plex Peripher Nerve Inj 2012; 7:4. 
28. Lawson VH, Gordon SA, Bromberg MB. Assessment of axonal loss in Charcot-MarieTooth neuropathies. Exp Neurol 2003; 184:753-757.

29. Shefner JM, Watson ML, Simionescu L, Caress JB, Burns TM, Maragakis NJ, et al. Multipoint incremental motor unit number estimation as an outcome measure in ALS. Neurology 2011; 77:235-241.

30. Allen MD, Choi IH, Kimpinski K, Doherty TJ, Rice CL. Motor unit loss and weakness in association with diabetic neuropathy in humans. Muscle Nerve 2013; 48:298-300.

31. Paramanathan S, Tankisi H, Andersen H, Fuglsang-Frederiksen A. Axonal loss in patients with inflammatory demyelinating polyneuropathy as determined by motor unit number estimation and MUNIX. Clin Neurophysiol 2016; 127:898-904.

32. Iwata A, Kunimoto M, Inoue K. Schwann cell proliferation as the cause of peripheral neuropathy in neurofibromatosis-2. Journal of the Neurological Sciences 1998; 156:201204.

33. Kara M, Akyuz M, Yilmaz A, Hatipoglu C, Ozcakar L. Peripheral nerve involvement in a neurofibromatosis type 2 patient with plexiform neurofibroma of the cauda equina: a sonographic vignette. Arch Phys Med Rehabil 2011; 92:1511-1514.

34. Gehlhausen JR, Park SJ, Hickox AE, Shew M, Staser K, Rhodes SD, et al. A murine model of neurofibromatosis type 2 that accurately phenocopies human schwannoma formation. Hum Mol Genet 2015; 24:1-8.

35. Zaidman CM, Harms MB, Pestronk A. Ultrasound of inherited vs. acquired demyelinating polyneuropathies. J Neurol 2013; 260:3115-3121.

36. Grimm A, Vittore D, Schubert V, Rasenack M, Decard BF, Heiling B, et al. Ultrasound aspects in therapy-naive CIDP compared to long-term treated CIDP. J Neurol 2016; Mar 26. [Epub ahead of print] 
37. Padua L, Granata G, Sabatelli M, Inghilleri M, Lucchetta M, Luigetti M, et al. Heterogeneity of root and nerve ultrasound pattern in CIDP patients. Clin Neurophysiol $2014 ; 125: 160-165$.

38. Brzezinska BB. Sonographische Befunde. In: Nenning BB, Gutjahr P, editors. Neurofibromatose Typ 1: Die Rolle der bildgebenden Diagnostik. Köln: Deutscher Ärzte-Verlag; 2006. p 43-52.

39. Kara M, Yilmaz A, Ozel S, Ozcakar L. Sonographic imaging of the peripheral nerves in a patient with neurofibromatosis type 1. Muscle Nerve 2010; 41:887-888.

40. Karabacak E, Tekin L, Carli AB, Akarsu S, Ozcakar L. Ultrasound imaging for neurofibromatosis: from the dermatologist's perspective. J Dtsch Dermatol Ges 2014; $12: 420-422$.

41. Ryu JA, Lee SH, Cha EY, Kim TY, Kim SM, Shin MJ. Sonographic differentiation between schwannomas and neurofibromas in the musculoskeletal system. J Ultrasound Med 2015; 34:2253-2260.

42. Trivedi R, Byrne J, Huson SM, Donaghy M. Focal amyotrophy in neurofibromatosis 2. J Neurol Neurosurg Psychiatry 2000; 69:257-261.

43. Schulz A, Baader SL, Niwa-Kawakita M, Jung MJ, Bauer R, Garcia C, et al. Merlin isoform 2 in neurofibromatosis type 2-associated polyneuropathy. Nat Neurosci 2013; $16: 426-433$.

44. Schulz A, Kyselyova A, Baader SL, Jung MJ, Zoch A, Mautner VF, et al. Neuronal merlin influences ERBB2 receptor expression on Schwann cells through neuregulin 1 type III signalling. Brain 2014; 137:420-432.

45. Schulz A, Zoch A, Morrison H. A neuronal function of the tumor suppressor protein merlin. Acta Neuropathol Commun 2014; 2:82. 
46. Plotkin SR, Albers AC, Babovic-Vuksanovic D, Blakeley JO, Breakefield XO, Dunn CM, et al. Update from the 2013 International Neurofibromatosis Conference. Am J Med Genet A 2014; 164A:2969-2978. 
TABLE 1.

Cross sectional areas along the median nerves of NF2 patients.

\begin{tabular}{|c|c|c|c|}
\hline $\begin{array}{c}\text { cross sectional area } \\
\text { CSA }\end{array}$ & $\begin{array}{c}\text { NF2 } \\
\text { patients }\end{array}$ & & \\
\hline right median nerve & number & mean $\left(\mathrm{mm}^{2}\right)$ & $\pm \mathrm{SD}$ \\
\hline carpal tunnel & 13 & 7.77 & 1.64 \\
\hline $1 / 3$ of the forearm & 14 & 7.79 & 2.72 \\
\hline at the elbow & 14 & 8.86 & 2.74 \\
\hline $1 / 2$ of the upper arm & 14 & 8.64 & 2.10 \\
\hline left median nerve & & & \\
\hline carpal tunnel & 12 & 9.33 & 4.40 \\
\hline $1 / 3$ of the forearm & 12 & 7.33 & 1.30 \\
\hline at the elbow & 12 & 9.00 & 2.30 \\
\hline $1 / 2$ of the upper arm & 12 & 9.83 & 2.82 \\
\hline
\end{tabular}

36

37

38

39

40

41

42

43

44

45

46

47

48

49

50

51

52

53

54

55

56 


\section{TABLE 2.}

Number and size of schwannoma-like fascicular enlargements in the median nerves of NF2 patients

\begin{tabular}{|c|c|c|c|c|}
\hline $\begin{array}{c}\text { nerve } \\
\text { lesions } \\
\text { number }\end{array}$ & $\begin{array}{c}\text { NF2 } \\
\text { patients }\end{array}$ & $\begin{array}{c}\text { diameter } \\
\mathbf{1 . 6}-\mathbf{2 . 5} \\
\mathbf{m m}\end{array}$ & $\begin{array}{c}\text { diameter } \\
\mathbf{2 . 6}-\mathbf{5 . 0} \\
\mathbf{m m}\end{array}$ & $\begin{array}{c}\text { diameter } \\
\mathbf{5 . 0} \\
\mathbf{m m}\end{array}$ \\
\hline $\begin{array}{c}\text { right } \\
\text { median nerve }\end{array}$ & $\mathrm{n}=14$ & & & \\
\hline no lesion & 5 & & & \\
\hline 1 & 3 & 1 & 2 & \\
\hline 2 & 3 & 3 & 3 & \\
\hline 3 & 1 & 1 & 1 & 1 \\
\hline 4 & 1 & 1 & 2 & 1 \\
\hline$\geq 5$ & 1 & 3 & 4 & 2 \\
\hline left & $\mathrm{n}=12$ & & & \\
\hline median nerve & 6 & & & \\
\hline no lesion & & & & \\
\hline 1 & 1 & 1 & 1 & \\
\hline 2 & 3 & 3 & 6 & \\
\hline 3 & 1 & 2 & 2 & \\
\hline 4 & 1 & 6 & 2 & 3 \\
\hline$\geq 5$ & & &
\end{tabular}




\section{,FIGURE LEGENDS}

FIGURE 1. Examples of CMAP scan analyses in three NF2 patients (A, B, C). The left column illustrates examples of CMAPs recorded from APB after stimulation of the median nerve at the wrist with subthreshold to supramaximal stimulation. The peak amplitudes (measured from base to the negative maximum) of all CMAPs are plotted for the various stimulation strengths (middle column). In the right column, the MScanFit program was used to derive a model with several SMUPs of different amplitudes to match the stimulus-response plots in the center column. The maximal number of functionally intact motor units and the mean voltage amplitude of the SMUPs for patients A, B, and C are given as insets in the middle and right column.

FIGURE 2. Statistical analyses. The number of functionally intact motor units was tested for a possible correlation with other parameters. The insets in all graphs show the results of the fit with regression lines. Low numbers of SMUPs in APB do not show a correlation with the nerve $\mathrm{CV}$ in the forearm or upper arm (B). There is, however, a statistically significant correlation with the peak amplitude of the CMAP, the mean amplitude of SMUPs, and the voltage amplitude of the largest SMUP.

FIGURE 3. Summary of MScan MUNE data in NF2 patients and from 26 median nerves of 18 control subjects. The maximal amplitude of the CMAP, the number of functionally intact motor units, and the mean amplitude of SMUPs are illustrated in scatter $(\mathbf{A}, \mathbf{C})$ and dot plots (B, D). The bars in B, D indicate mean \pm SE.

FIGURE 4. Examples of "nerve lesions" (i.e. schwannoma-like fascicular enlargements) in a NF2 patient. Longitudinal $(a, b, c)$ and transverse $(d, e, f)$ sonograms of the right median 
nerve reveal well defined "lesions" of different diameters: (d) $>7 \mathrm{~mm}$, (e) about $4 \mathrm{~mm}$, (f) about $2 \mathrm{~mm}$. The "lesions" show a middle to low homogeneous echogeneity and are located in direct continuity of the nerve inside the hyperechogenic epineurium. The outer borders of the nerve and the schwannoma-like fascicular enlargements are marked by yellow dotted lines.

FIGURE 5. Correlation of findings in high resolution US nerve imaging with the number of functionally intact motor units detected by CMAP scan MUNE. The number (A) and the diameters of the largest schwannoma-like fascicular enlargements (B) in an affected nerve are illustrated. (A) Data from 20 median nerves of 14 NF2 patients. (B) Data from schwannomalike fascicular enlargements detected in 11 median nerves from 9 NF2 patients. The insets show egression line statistics. 
A
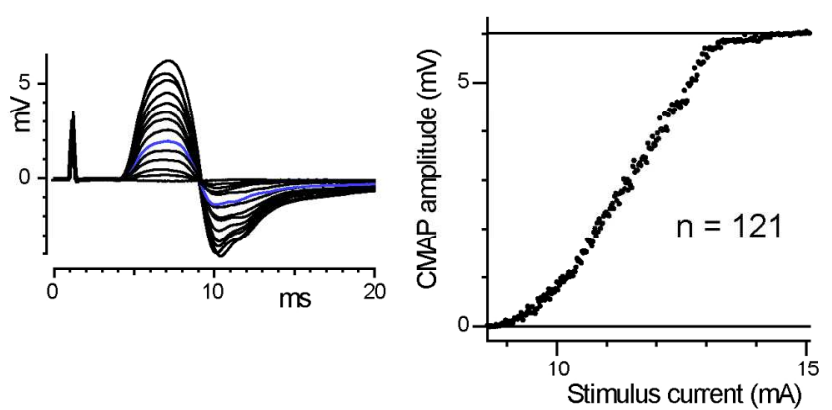

B

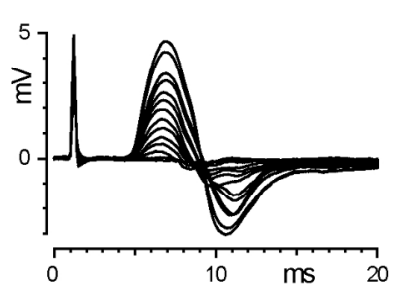

C

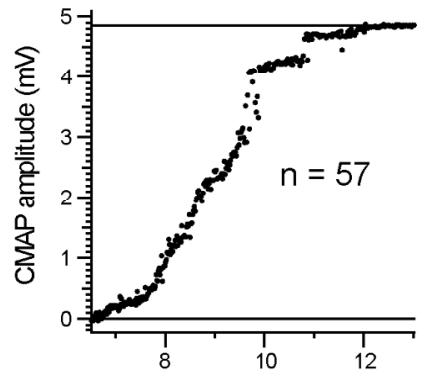

Stimulus current (mA)

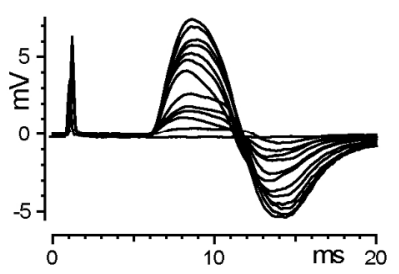

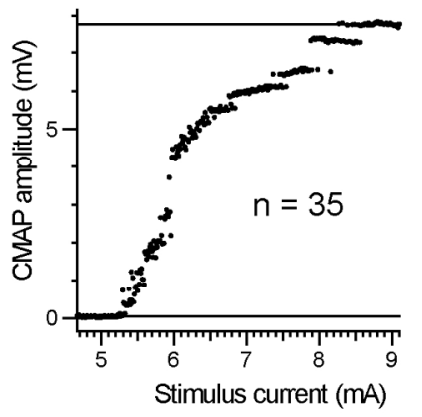
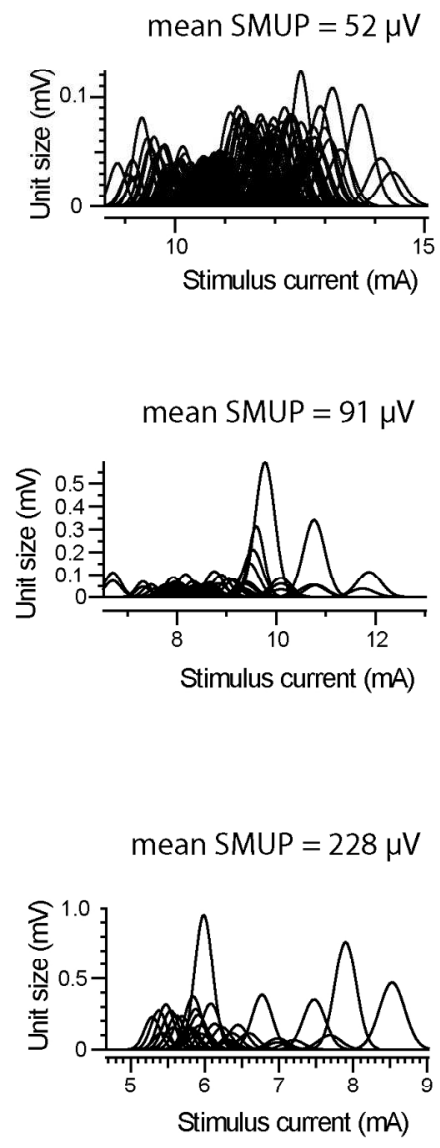

FIGURE 1. Examples of CMAP scan analyses in three NF2 patients (A, B, C). The left column illustrates examples of CMAPs recorded from APB after stimulation of the median nerve at the wrist with subthreshold to supramaximal stimulation. The peak amplitudes (measured from base to the negative maximum) of all CMAPs are plotted for the various stimulation strengths (middle column). In the right column, the MScanFit program was used to derive a model with several SMUPs of different amplitudes to match the stimulusresponse plots in the center column. The maximal number of functionally intact motor units and the mean voltage amplitude of the SMUPs for patients $A, B$, and $C$ are given as insets in the middle and right column. $169 \times 165 \mathrm{~mm}(300 \times 300 \mathrm{DPI})$ 
A
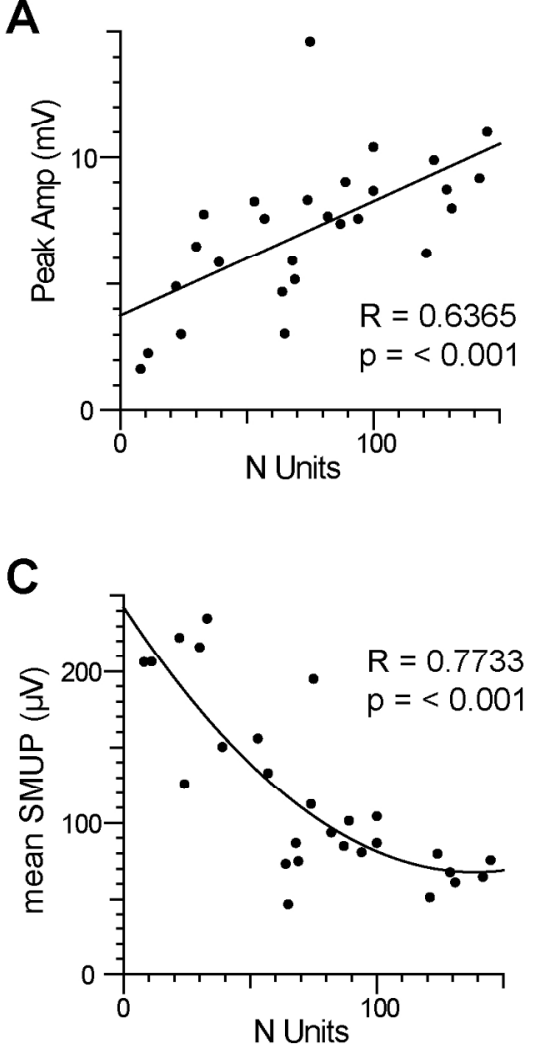

B 70 upper arm
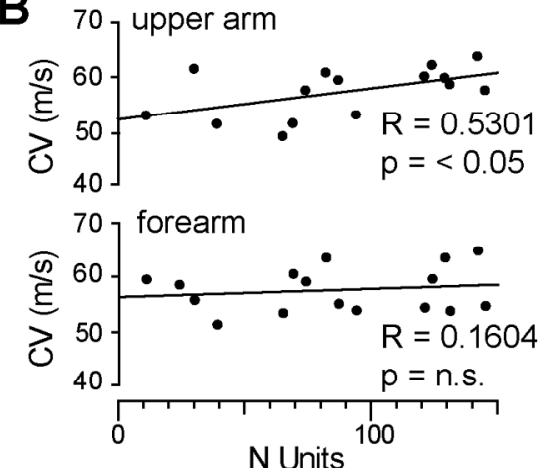

D

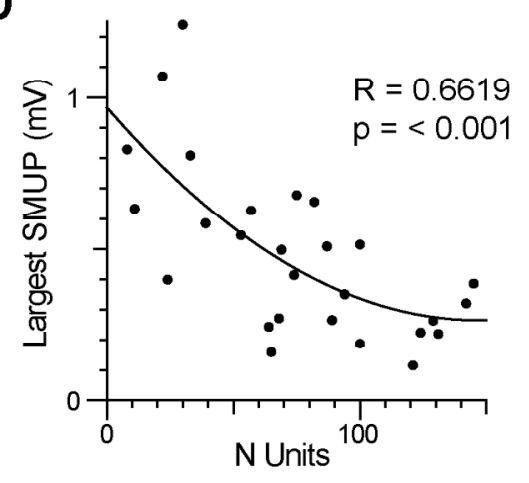

,FIGURE 2. Statistical analyses. The number of functionally intact motor units was tested for a possible correlation with other parameters. The insets in all graphs show the results of the fit with regression lines. Low numbers of SMUPs in APB do not show a reduction of the nerve conduction velocity in the forearm or upper arm (B). There is, however, a statistically significant correlation with the peak amplitude of the CMAP, the mean amplitude of SMUPs, and the voltage amplitude of the largest SMUP $(A, C, D)$. $171 \times 157 \mathrm{~mm}(300 \times 300 \mathrm{DPI})$ 


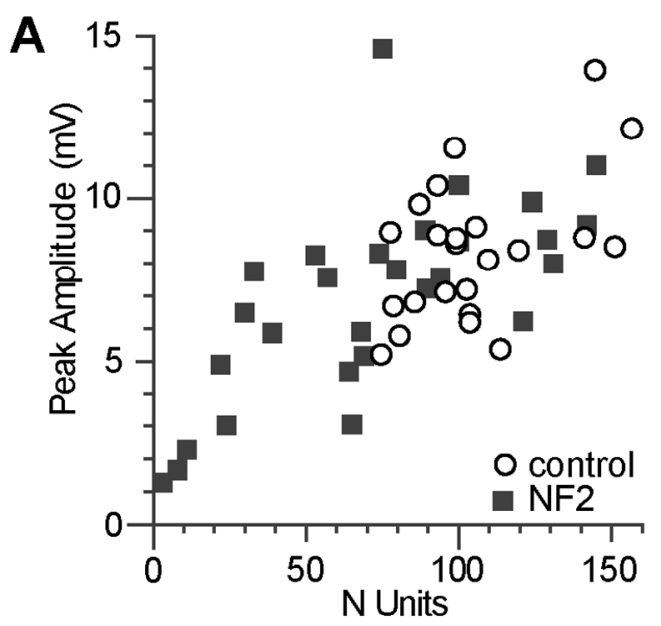

B
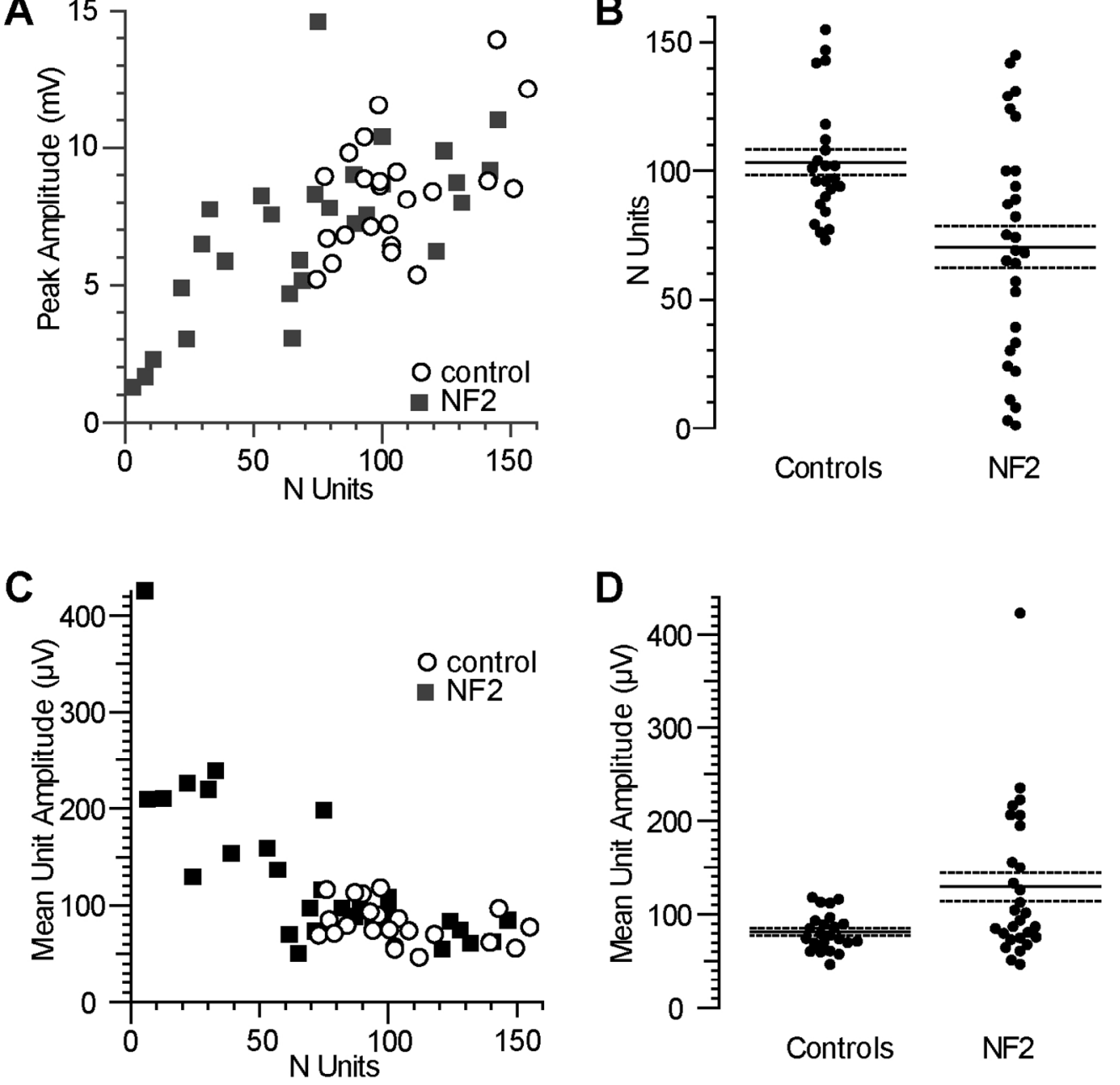

D

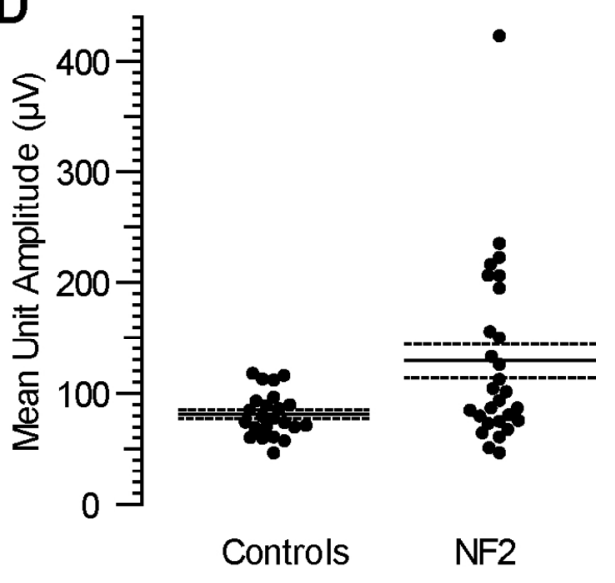

FIGURE 3. Summary of MScan MUNE data in NF2 patients and from 26 median nerves of 18 control subjects. The maximal amplitude of the CMAP, the number of functionally intact motor units, and the mean amplitude of SMUPs are illustrated in scatter $(A, C)$ and dot plots $(B, D)$. The bars in $B, D$ indicate mean + SE.

$127 \times 128 \mathrm{~mm}(300 \times 300 \mathrm{DPI})$ 

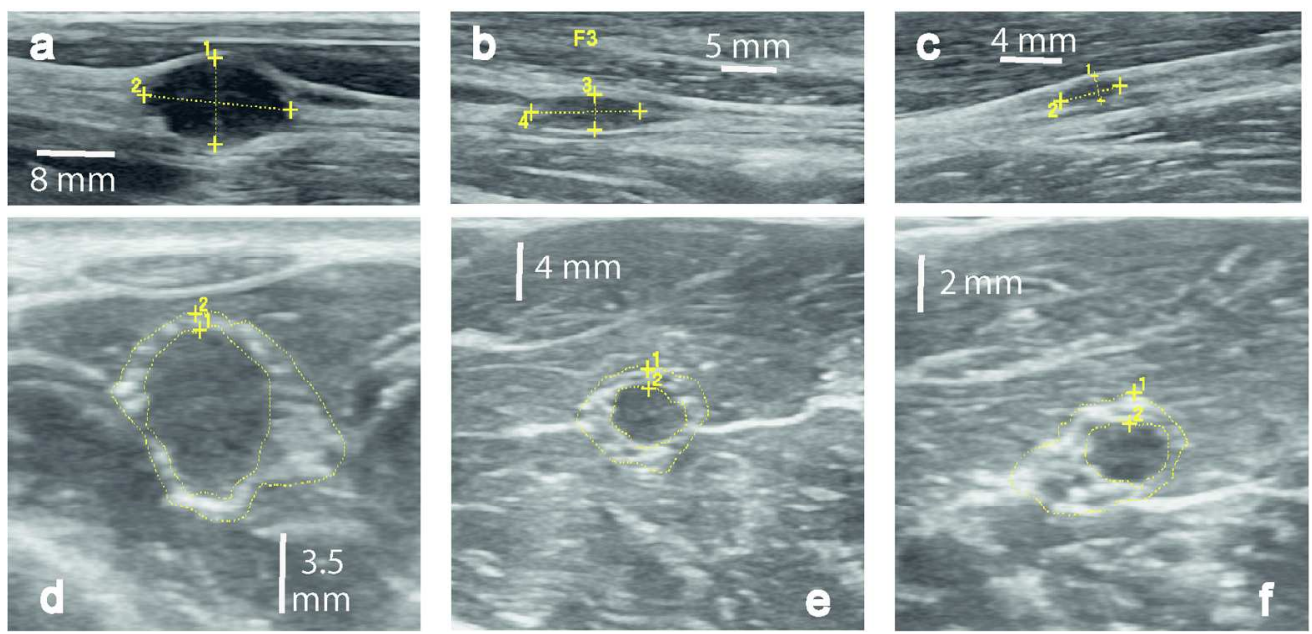

FIGURE 4. Examples of "nerve lesions" (i.e. schwannoma-like fascicular enlargements) in a NF2 patient. Longitudinal $(a, b, c)$ and transverse $(d, e, f)$ sonograms of the right median nerve reveal well defined "lesions" of different diameters: (d) $>7 \mathrm{~mm}$, (e) about $4 \mathrm{~mm}$, (f) about $2 \mathrm{~mm}$. The "lesions" show a middle to low homogeneous echogeneity and are located in direct continuity of the nerve inside the hyperechogenic epineurium. The outer borders of the nerve and the schwannoma-like fascicular enlargements are marked by yellow dotted lines. $151 \times 72 \mathrm{~mm}(300 \times 300$ DPI $)$ 

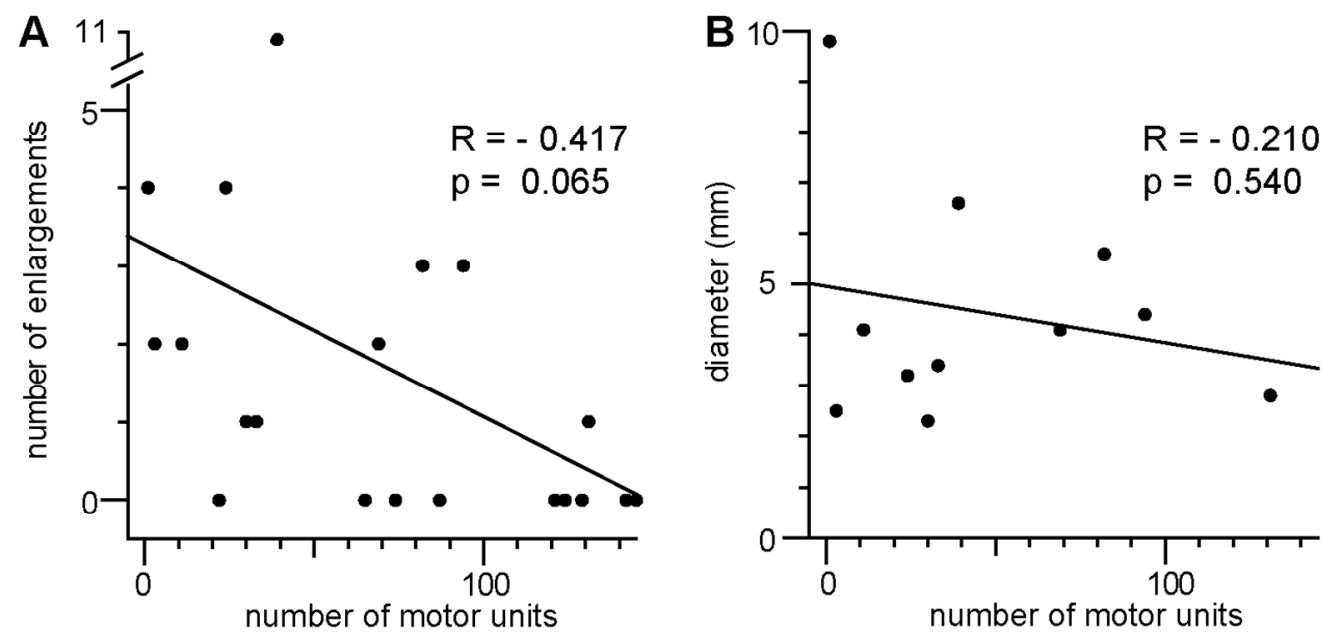

FIGURE 5. Correlation of findings in high resolution US nerve imaging with the number of functionally intact motor units detected by CMAP scan MUNE. The number $(A)$ and the diameters of the largest schwannomalike fascicular enlargements (B) in an affected nerve are illustrated. (A) Data from 20 median nerves of 14 NF2 patients including those patients without a "nerve lesion". (B) Data from schwannoma-like fascicular enlargements detected in 11 median nerves from 9 NF2 patients. The insets show egression line statistics. $128 \times 61 \mathrm{~mm}(300 \times 300 \mathrm{DPI})$ 